\title{
Desumano, demasiado humano: Endgame
}

\author{
Sebastiana Fadda
}

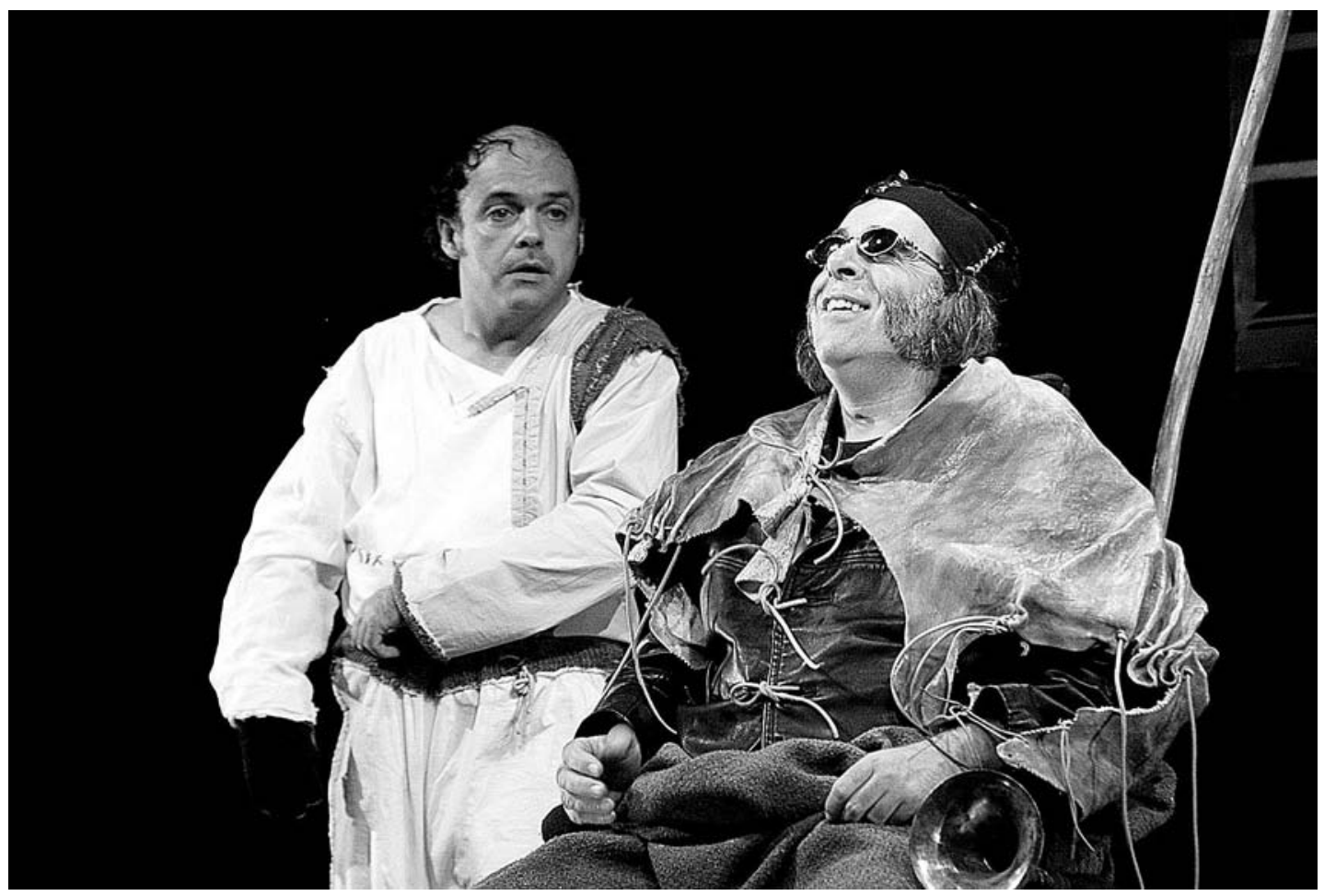

Titulo: Endgame (Fin de partie, 1957; Endgame, 1958). Autor: Samuel Beckett. Tradução: Francisco Luís Parreira. Encenação: Bruno Bravo. Cenografia: Stéphane Alberto. Figurinos: Chissangue Afonso. Desenho de luz: Miguel Seabra e Bruno Bravo. Interpretação: Gonçalo Waddington (Nagg), João Lagarto (Hamm), Miguel Seabra (Clov), Raquel Dias (Nell). Co-produção: Teatro Meridional e Primeiros Sintomas. Local e data de estreia: Espaço Karnart, Lisboa, 28 de Abril de 2004.

Fin de partie é a peça que confirma o êxito alcançado por Samuel Beckett com En attendant Godot, estreada em Paris nos primeiros dias de Janeiro de 1953, no Théâtre Babylone, numa encenação de Roger Blin.

Essa data é um marco incontornável na história do teatro do século XX, e por vários motivos. A cena passa a ser um lugar de acção e imobilidade com objectivos indefinidos, de palavras e silêncios com gratuidade aparente, de jogos cénicos com sentido ambíguo e motivação escorregadia. É a negação do teatro assente nas teorias aristotélicas, a recusa da função digestiva do teatro burguês, a descrença na capacidade dialéctica do teatro revolucionário. Falta, em geral, um esqueleto narrativo e as personagens deslocam-se no palco oscilando entre as fronteiras da normalidade e da patologia. A filosofia existencialista faz o seu ingresso no teatro dispensando comentários, substituindo a abstracção da teoria pela exibição de situações extremas. Regista-se, também, a confluência dos movimentos vanguardistas que animaram os meios artísticos e culturais a partir de finais do século XIX, razão pela qual a linguagem se torna protagonista da cena, mesmo pela denúncia feita através do silêncio. Na génese deste teatro,

convencionalmente chamado "do absurdo" residem, portanto, principalmente inquietações filosóficas, artísticas, culturais e religiosas, às quais se acrescentaria uma determinada postura intelectual perante os horrores da história da humanidade do século XX.

Não se identifiquem, porém, o espanto e a impotência perante as atrocidades de duas guerras mundiais, e da própria condição humana em geral, com a passividade. No caso de Beckett, por exemplo, esses mesmos sentimentos, analisados à lupa na cena, são resgatados na vida pela participação na resistência francesa contra as invasões nazis. E é essa a configuração da atitude assumida pelas suas personagens: espantadas, horrorizadas, existem e resistem. Apesar de tudo e contra toda a lógica. Contra toda e qualquer 
circunstância, as personagens beckettianas assemelham-se a seres "limiares" que existem e restistem, agarradas à palavra, ao gesto, à memória, nem que estes se transformem em sucedâneos do presente e da vida. Na sua tendência para a interiorização e o isolamento, o espírito ascético de Beckett cria assim um teatro em que os símbolos do deserto e das cinzas, atingindo uma dimensão quase mistica, mas profana e poética, bem sintetizariam a sua visão do mundo.

A impermanência e a vacuidade das coisas e das situações, a inelutabilidade da deterioração determinada pelo tempo, depois de preencher o espaço ilusoriamente aberto de En attendant Godot, povoam o espaço explicitamente fechado de Fin de partie.

A crítica mais informada discorda acerca das datas de redacção desta peça. Para uns remontaria a 1952, para outros a 1954 ou até 1955, quase na unanimidade concordam que já se encontraria ultimada em 1956. A versão final segue duas versões intermédias em dois actos, acabando por os condensar num só. A estreia absoluta acontece em Londres, a 1 de Abril de 1957, no Royal Court Theatre, com encenação de Roger Blin e interpretação do próprio encenador no papel de Hamm, que contracena com Jean Martin (Clov), Christine Tsingos (Nell) e George Adet (Nagg). Esse espectáculo é estreado poucas semanas a seguir em Paris, a 26 de Abril de 1957, no Théâtre des Champs-Elysées, havendo como única alteração a presença de Germaine de France no papel de Nell. Em 1958 o autor verte o texto para inglês, intitulando-o Endgame.

Em Portugal já houve várias versões com diversos títulos. Entre elas Fim de festa (1970, com encenação de Júlio Castronuovo), Final (1989, com encenação de Mário Viegas) e Última jogada (1996, com encenação de Ana Tamen). Apaixonado jogador de xadrez, é visivelmente no tabuleiro que Beckett vai buscar inspiração e encontra o título certo para a sua segunda peça de fama internacional. Os jogos estão feitos, já não há nada nem ninguém a esperar, já não há natureza nem salvação possível, por autoenganadora que seja. Xeque-mate aos homens, a quem a vida reserva a derrota desde a primeira jogada, porque a primeira respiração é portadora também da última.

A recente produção do Teatro Meridional / Primeiros Sintomas baseia-se na redacção inglesa e dela mantém o título original, o que permitiria a imediatez da identificação, bem como a preservação da secura e incisividade que o autor quis imprimir ao texto em geral. Mesmo tratando-se no caso em questão de uma língua sintética e não analítica (daí a maior secura), na verdade a opção efectuada pelo tradutor é claro sintoma da inegável função de língua franca desempenhada pelo inglês na sociedade ocidental e na cultura juvenil contemporânea (mas também nos meios político-financeiros internacionais). E é desde as primeiras falas de Clov ("Acabou. Está acabado. Quase acabado"), até às derradeiras palavras proferidas por Hamm ("Trapo imundo. Tu permaneces"), que a essencialidade da linguagem beckettiana é transportada indemne para o português. Aliás, a esse sentido da economia da palavra corresponde o sentido da economia na cena, e ambos regem todo o espectáculo.

0 resultado é simplesmente belíssimo. Fiel sem ser servil, a encenação de Bruno Bravo respeita o espírito da peça como a tradução de Francisco Luis Parreira respeita a letra do autor. Há, contudo, leves afirmações de autonomia geradoras de novos pontos de força e de novas ressonâncias, sem cair nos perigos do desvio ou do empobrecimento do original. Vejam-se alguns exemplos concretos.

Beckett imagina um espaço cénico perfeitamente simétrico: uma porta à esquerda, os caixotes do lixo à direita; uma janela no fundo à esquerda e outra no fundo à direita, duma vê-se uma terra abandonada e da outra um mar deserto; Clov, o servo/figlio de Hamm afectado por uma doença que o impede de se sentar, fica em geral na zona esquerda do palco, enquanto Nagg e Nell, os velhos pais de Hamm, ocupam os caixotes do lixo colocados na zona direita; Hamm, o pai/patrão cego e paralítico, domina do seu miserável trono colocado no meio do espaço.

Ao reduzir a um acto os dois primitivos, todavia, Beckett decide romper com a simetria ao nivel da construção textual, 


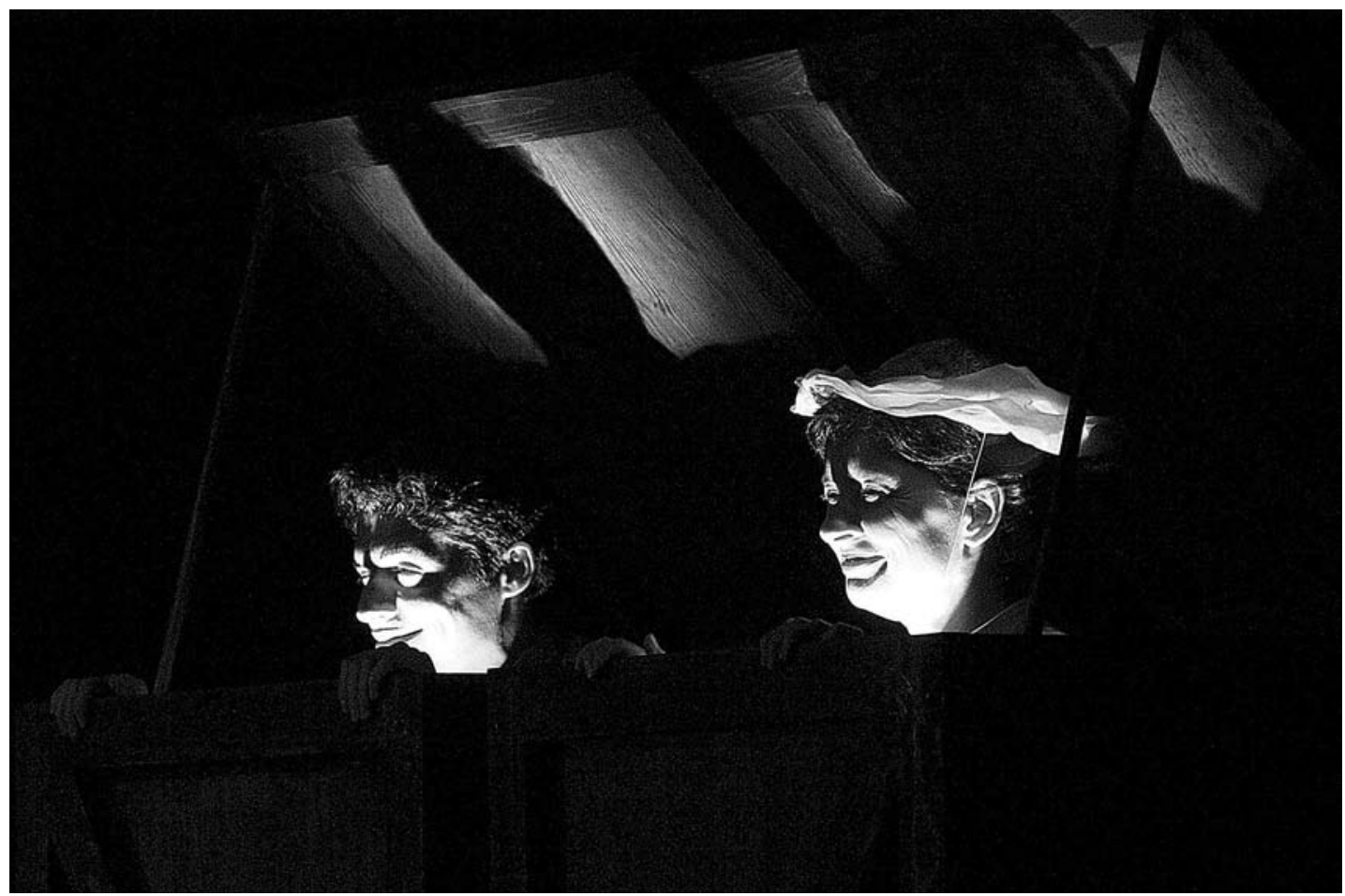

Gonçalo Waddington e

ou seja, aquela simetria procurada e mantida em En attendant Godot é abandonada. Tendo em conta também esse pormenor, não resulta abusiva a quebra da simetria ao nivel da cena praticada nesta encenação.

No lugar da porta há uma espécie de parede e as duas janelas fundem-se numa, situada no fundo à esquerda. Isso significa que as hipotéticas saídas ou pontos de possível fuga diminuem; quanto ao mundo exterior, é uniformizado e reduzido ulteriormente numa zona indistinta de terra/mar de ninguém. Hamm pede a Clov para que o leve até ao centro do centro desse minúsculo microcosmos, mas é inútil. Uma vez quebrada a simetria só estará sempre e de qualquer modo no centro da desordem. Esse pequeno deus impedido na visão e na motricidade é arrastado pela escuridão no meio do caos.

Os caixotes do lixo que deveriam acolher Nagg e Nell são substituídos por caixas de madeira e os dois deuteragonistas são interpretados por jovens actores. Infiltrase assim o paradoxo. Os pais, por viverem das suas memórias, podem ficar projectados atrás no tempo, na época da sua juventude, e por isso ser em cena mais novos do que o filho. Mas insinua-se também o grotesco. Se falar em falsete é uma alusão em chave tragicómica à infantilização da velhice, pelo contrário o semblante dos jovens, iluminados por um foco de luz vindo dos caixotes, torna-se espectral e remete para o facto de não poderem estar na fase residual (no caixote do lixo) por estarem já numa fase posterior (no caixão).

João Lagarto e Miguel Seabra, respectivamente nos papéis de Hamm e Clov, tiveram um desempenho exemplar. Na composição das personagens, João Lagarto retirou a Hamm os excessos de crueldade e soube dotar duma certa humanidade a sua criatura; Miguel Seabra conferiu a Clov a pungência e dignidade possuída pelos ofendidos conscientes da sua posição. Ambos, na verdade, foram capazes de expressar uma vasta gama de sentimentos e de registos, contracenando nos diálogos e nas pausas, harmonizando as cenas mais dramáticas com as mais moderadamente risonhas. As cenas mais intensas, onde o diálogo reincide sobre o conceito de progressiva decomposição da vida e do universo, ou sobre os interrogativos metafísicos e o anseio pelo tempo prémanifestação da vida, são mitigados pelo registo mais certo com que os actores permitem saborear o humorismo de certas passagens do texto, inclusive o gozo de Hamm a contar o seu romance, os tiques de Clov a subir o escadote ou a falar para dentro dos caixotes, ou ainda o som do claxon usado no passeio pelo espaço doméstico. Movimentando-se mais numa prisão do que num circo, contudo, João Lagarto e Miguel Seabra restituem por inteiro o delicado mecanismo tragicómico tão minuciosamente descrito por Beckett. Os actores mais jovens, Raquel Dias e Gonçalo Waddington, enfrentaram corajosamente este desafio. Contidos e convincentes quanto basta, conseguiram não exceder para a lado da caricatura, mas mesmo tendo evitado ridiculizar as suas personagens, talvez as pudessem enriquecer de maiores nuanças.

Contribuíram para a feliz recriação do teatro poético beckettiano, ainda, quer a cenografia, devidamente despojada segundo os preceitos do autor, quer os figurinos, de linha não datável para Hamm e Clov e mais datada para Nagg e Nell, reforçando a coerência desta encenação. Quanto à iluminação, que propiciava o efeito de uma intimidade dolorosa e comovedora no Espaço Karnart de Lisboa, devido à proximidade entre o palco e a plateia, criou efeitos vagamente retrò no Auditório Fernando Lopes Graça de Almada, graças a uma hábil reformulação do desenho de luzes que conseguiu colmatar a acrescida distância, envolvendo os espectadores com imagens em sépia, de gosto ao mesmo tempo antigo e actual, estranho e familiar.

0 teatro de Samuel Beckett continua a tocar e a surpreender, por saber dizer tanto, contando tão pouco. Porque afinal o (não) enredo de Fin de partie/Endgame resumir-se-ia ao que segue: Iuzes, Clov anuncia a agonia do universo, intermezzo, Hamm proclama a vitória do sudário, escuro. 